\title{
ORGANIZATIONAL DYNAMICS OF THE RISE OF TELEWORK AS AN ADAPTIVE RESPONSE TO A GLOBAL PANDEMIC
}

\author{
Darrell Norman BURRELL \\ The Florida Institute of Technology, Melbourne, Florida, USA \\ dburrell2@thechicagoschool.edu \\ Terila JOHNSON \\ Grand Canyon University, Phoenix, Arizona, USA \\ terilaj@gmail.com \\ Anton SHUFUTINSKY \\ Cabrini University, Radnor Township, Pennsylvania, USA \\ as4363@cabrini.edu \\ Dana-Marie RAMJIT \\ Walden University, Minneapolis, Minnesota, USA \\ dana-marie.ramjit@waldenu.edu
}

\begin{abstract}
The use of remote working options has saved jobs and reduced health risks inherent to the rise of COVID-19. The opportunity to use telework has allowed organizations to engage in operational activities by leveraging virtual teams potential. Organizations offering workers to work remotely have become financial salvation for many workers during the pandemic, significantly since the pandemic impacted the U.S. economy so severely that more than since more than 57 million American workers have filed for unemployment government benefits in just 2020. While having a telework option is an assurance of organizational sustainability or continual employment, it represents a unique opportunity for exploration for employees, supervisors, and organizations attempting to adapt to this evolving level of complex change. This paper uses applied qualitative focus group research from a process consulting to explore the values and barriers that telework for a real estate title organization called XRO.
\end{abstract}

KEYWORDS: COVID-19, telework, remote work, organizational development, organizational management, adaptive management

\section{Overview and Introduction}

This paper employs an applied qualitative research process consulting approach to explore telework utilities' values and barriers. To develop a framework for understanding the appreciative qualities and useable telework applications at an organization identified as
XRO, a real estate title company. The name $\mathrm{XRO}$ is used for this study to protect the actual firm's privacy and intellectual property that produced this data. Focus groups were conducted related to telework. A core principle of action and applied research includes the organization participants who have historical knowledge 
and implement the recommendations and benefit from the solutions. The applied qualitative research focus group consisted of 20 participants divided into five small discussion groups of 4 individuals developed by opportunistic sampling from organizational employees. Focus group participants included participants (Ten managers and ten employees) that had never previously engaged in telework before COVID-19. The group was mixed with an equal number of managers and an equal number of employees. The sampling method was judgmental and based on a core team directly assigned to work on senior organizational management's telework implementation task force. The goal was to consider telework and its implementation from a framework that was positive.

Teams are inherently complex, as they are impacted by numerous factors that affect group dynamics (Burrell, 2020), and this is not absent in virtual teams. The COVID-19 pandemic has exacerbated the already existing disruption of the Fourth Industrial Revolution, increasing the transition of organizational work into virtual environments, and significantly changing how work is accomplished in organizations (Burrell, 2020), how virtual teams collaborate, and how virtual work is managed (Gelston, Wells, \& Dalton, 2018; Shufutinsky et al., 2020a; 2020b). It has been approximated that the percentage of workers in the U.S. population that have switched to working from home (WFH) because of COVID-19 ranges anywhere from $34 \%$ to $62 \%$ o (Katsabian, 2020). Organizations have become increasingly concerned with how the COVID-19 pandemic has contributed to accelerating the processes by which work is accomplished in the age of continual and rapid technological advancements (Katsabian, 2020; Shufutinsky et al., 2020) as this acceleration of work processes and shifts to new and changing work methods, along with the already disruptive technological advancements, may have considerable implications on how teams interact and whether organizations can be useful in this new normal of continuous virtual workplaces.

Typically, virtual teams vary in the way work is accomplished. This variance can include them being co-located, geographically dispersed, or combined, including routinely mobile members (Burrell, 2020). These conditions provide different avenues of meetings, communication, and work, including distance communication via e-mail, voicemail, or other communication technologies, co-located face-to-face meetings, or a combination, depending on the distribution of employees and business units (Martin, 2018; Quisenberry, 2018; Shufutinsky et al., 2018). Managing teams is challenging, yet the potential for problems and team conflicts can increase when managing virtual teams (Quisenberry, 2018). These problems can be driven by or even create a lack of trust, miscommunication, lack of collaboration, technical interruptions, digital micromanagement, and knowledge sharing failure (Hagy, 2018; Burrell 2020). Virtual teams are challenged by unique problems with trust, relationship building, power distance, time schedules, project coordination, and collaboration (Burrell, 2020).

Communication and collaboration are even more critical for trust, relationship building, project coordination, and virtual team formation and management (Burrell, 2020). Of particular concern is that the COVID-19 pandemic has shifted millions of people to teleworking or virtual work, from home-offices and employees' private spheres (Katsabian, 2020).

The acceleration of work processes, the acceleration of technological advancements, and a home office's hybrid nature prove to have implications on how virtual teams communicate, interact, collaborate, and manage work. Telework is defined as work performed at home or from 
an alternate or satellite office to reduce commuting (Shin, El Sawy, Sheng, and Higa, 2000). The term telework has also been used to describe a type of virtual remote business workplace ecosystem. This type of negotiated work environment has continued to grow with the increase of globalization, paired with emerging and advancing technological power, capability, and capacity, particularly in large corporate or government enterprises (Shufutinsky et al., 2018). With limited options available to corporations, governments, and nonprofits, the COVID-19 pandemic has pushed the rapid implementation of this workplace dynamic across industries, nations, and organization types, driving potential for a post-pandemic semi-permanent telepresence work environment (Burrell, 2020).

\section{Review of Literature}

Virtual work or telework can work from home or a remote office location (Shaver, 2003). Additionally, virtual meeting platforms have been increasingly used by organizations to advance telepresence, which is the ability of people at remote locations to appear present to one another during communication (Shufutinsky et al., 2018). Expertise and experience are needed in managing remote teams (Burrell, 2020).

Telework can also be referred to as telecommuting, an alternative work arrangement involving telematics technology, developed since the 1970s (Belzunegui-Eraso \& Erro-Garcés, 2020). It is not solely working from home but working outside of an employer's building with ICTs as the central support system. Hence, it can occur from several modalities such as telework from home, mobile telework, freelance telework in small office/home office (SOHOs), and telework at shared facilities (Baruch \& Nicholson, 2000; Chung, 2018).
Teleworkers are professionals and highly skilled workers who perform duties that entail producing, assessing, and presenting data for multiple contexts, and therefore, are likely to be higher educated, and with higher income levels than the rest of the working population, and makeup what is referred to as a knowledge society (Taskin \& Bridoux, 2010; Alvesson, 2004).

There are numerous reasons organizations permit or establish telework or virtual work for their employees, besides simple scheduling needs or requests by employees (Burrell, Barnard-Zaffino, \& Ulomi, 2014). These reasons include actionable organizational plans for corporate social responsibility around environmental sustainability, diversity, and inclusion, as well as for corporate efficiency and economic benefits (Burrell, 2020). Corporations are also increasing interest in growing telework policies and programs to accommodate work-life balance and family needs and improve organizational culture, which results in more effective and efficient work and productivity (Burrell, Barnard-Zaffino, \& Ulomi, 2014). Corporations are also increasing in the use of independent contractors and gig-economy workers, saving office space, among other costs (Ciulli \& Kolk, 2019; Green, 2018; Tan-Solano \& Kleiner, 2001). Additionally, organizations have found telework to accommodate and retain the disabled workforce (Burrell, Barnard-Zaffino, \& Ulomi, 2014).

Teleworking or work from home or other alternate locations is a workplace phenomenon that has grown in frequency, popularity, and prevalence in the private industry in the United States and globally, even before the 2020 COVID-19 pandemic (Burrell, 2020). The early impetus that fostered virtual work has shifted from a corporate social responsibility issue focused on reducing and diminishing the environmental impact of more cars on the 
road to a more comprehensive series of reasons and justifications, ranging from energy conservation to corporate cost savings on office space rentals, to quality of work-life aspects like reducing stressful employee commutes (Burrell, BarnardZaffino, \& Ulomi, 2014). Managers need to develop a level of comfort, understanding, and trust for allowing employees to have discretion about how and when work projects are done (Chan, Beckman, \& Lawrence, 2007; Burrell, 2020).

The use of remote workers is not unusual. Evidence suggests that remote work is being readily adopted by organizations when there is a need for specific capability and subject matter expertise to be integrated into a team (Burrell, 2020). In an investigation into the realities of remote work, Deshpande et al. (2016) found that remote work disadvantages include isolation and being excluded from the small team's knowledge network. However, advantages included the ability to focus on the task at hand and a higher degree of personal and professional validation because of the interactive, social way collaboration and work activities are conducted (Burrell, 2020; Burrell, BarnardZaffino, \& Ulomi, 2014). Transparency and visibility are also fundamental for projectrelated activities to strengthen a remote team's effectiveness and cohesiveness (Burrell, 2020).

Telework adoption and use of remote work are concerned, it is critical to identify remote teams' management in innovation in organizational strategy (Burrell, 2020). Having discussed telework thus far, it is essential to review remote teams' design to discuss the importance of managing remote teams (Burrell, 2020). Analysis and discussion on managing remote teams from a design management perspective thus far, having noted by amounts to understanding how organizations can manage remote teams as an essential aspect of organizational strategy (Silva \& Merino, 2017).
Consequently, remote teams can also promote collaboration and creativity. Still, involvement and interaction are critical to promote a healthy and functional organizational system (Silva \& Merino, 2017) and align with the corporate mission and vision. Like other organizational teams, remote teams must be involved, engaged, and approached systemically through an organization development lens.

Organizational development (O.D.), as a field of practice, is grounded in the behavioral, social, and basic sciences that engage human systems in organizations and communities to develop system-wide capacity, effectiveness, and well-being (Shufutinsky et al., 2020). This grounding includes doing the necessary work to transform organizations, extend human potential, and increase system-wide capacity and well-being (Cummings \& Worley, 2008).

\subsection{Beyond Both Lewin and the} Adjustment for Temporal Approximation

Lewin's theory regarding planned organizational change - organization development - has been held in high accord and used historically to address change in organizations, mainly using the linear and sequential unfreeze-change-refreeze model (Bartunek \& Woodman, 2015; French \& Bell, 1999). Nevertheless, this model has been criticized for over-simplicity in use by many Organizational development (O.D.) and non-OD scholars and practitioners alike. Similar to the understanding of organizational research, and the use of narratives, stories, experiential components, and other data that have been criticized historically as incomplete as a result of being dimensionally inadequate with linearity and sequence and ignorant of additional aspects of temporality (Boje, 2018; Connelly \& Clandinin, 2006; Shufutinsky, 2019a; 2019b), the traditional Lewinian framework has been critiqued for inconsideration of temporality in the model's design and implementation 
(Bartunek \& Woodman, 2015; Marshak, 1993). The solution for this misalignment and the direction to bring O.D. into the modern era has been the establishment and implementation into practice and scholarship of the framework of the New Dialogic O.D., which is dialogics-centric (Bushe \& Marshak, 2009) and portends to consider the temporal aspect into the change process. In this framework, there is a modular accommodation to timing and sequence and pacing, rhythm, and polyphonic dimensions that impact the organizational change (Bartunek \& Woodman, 2015). However, what is potentially still missing from this new dialogic framework is the attention not only to temporality but to spatiality. Individuals experience organizations from a social and temporal orientation and regarding space and setting (Connelly \& Clandinin, 2006; Shufutinsky, 2019). The work's location determines space and shifting distance from what has been normalized or routine can influence interpretation, mood, and social interaction of the researcher and participant (Connelly \& Clandinin, 2006), both positively and negatively. Spatiality has to do with the interaction with location, but also with regards to the unorthodoxy of space as it applies in Industry 4.0 and the age of technological advancement in which space is not a finite physical location alone (Burrell, Barnard-Zaffino, \& Ulomi, 2014; Burrell 2020).

Effective business management, requires that organizations stay true to those O.D. foundations of employee and organizational development, regardless of whether it is in person or the virtual environment (Cummings \& Worley, 2008). As such, virtual teams should be approached and designed with consideration of socio-technical systems theory, organizational transition, systems thinking, and advanced adaptive leadership styles (Burrell, 2020).

\subsection{Sociotechnical Systems Theory}

In the workplace, employees engage in numerous ways and with different interactions with their work, with each other, and with their work equipment and computer technologies (Burrell, 2020). Essentially, these interactions are what creates a socio-technical work environment. The term socio-technical refers to the interrelatedness of work's social and technical aspects (Burrell, 2019). This concept addresses the human-systems integration aspect of the work in which both the human and the technological systems are pertinent to the work (Cummings \& Worley, 2008; Burrell, 2019).

Socio-technical theory is founded on the principles that social and technical factors in the workplace create the conditions for successful or unsuccessful system performance (Cummings \& Worley, 2008; Burrell, 2019). As the theory literature describes, the inevitability of mixing the 'socio' with the 'technical' is that the two do not necessarily behave like each other because people are not machines. Thus, when placed in scenarios of increased socio-technical interactions and reduced socio-social interactions, there is a potential for growing complexity and interdependence, and the behaviors of both the social and technical aspects of the work can potentially exhibit non-linear behavior patterns and results (Rousseau, 1977; Walker, Stanton, Salmon, \& Jenkins, 2008). This theory outlines why organizations and organizational leadership should be able to strategize and prepare for telework programs, virtual teams, and tele-present work, with significant consideration for effective transitions, especially in unexpectedly rapid shifts, such as during discontinuous change that comes with events like the COVID-19 pandemic (Burrell, 2020). 


\subsection{Organizational Transition}

It is no secret in organizational sciences that organizational change is inherent. Situations, conditions, environments, and behaviors change as the world changes when organizations experience massive disruptions such as COVID-19, and technologies emerge (Burrell, 2020). With these types of changes, organizational shifts create the need for significant transitions. Although the two are critically related, they are not the same, as change is an external process that leads to evolution, which is internal (Bridges, 2009). Without significant transitions, organizations can undergo organizational catastrophe or failure (Bridges, 1991, 2009; Brisson-Banks, 2010). Therefore, this adjustment process is necessary through organizational changes such as planned or unexpected shifts, virtual work, and virtual team formation. Transitions present some specific and distinct challenges for organizations and their members, particularly concerning professional growth and personal wellbeing. Therefore, this topic should be given an avid amount of time and consideration, depending on the organization, the individuals changing, and the circumstances or conditions under which they undergo them, including planned or unplanned transitions (Schlossberg, 2011). Bridges' (2004) three-stages concept exhibits the essential nature of transitions, requiring letting go of certain aspects of the self, letting go of former roles or situations, and learning how to deal with new functions and environments (Shufutinsky, 2019a), such as what organizations must go through during a transition to telework, virtual communications, and virtual team development. These are not simple changes, and they do potentially create environments of chaos and some sense of volatility and complexity, potentially shocking the organizational system. Systems theory identifies organizations as whole units, thus exemplifying the interconnectedness of all of an organization's parts (Burrell, 2019). Because many organizations, especially large organizations such as government agencies, are complex adaptive systems, there is no analysis or response to a single element or component of an organization that will significantly change the entire system (Quisenberry, 2018). Systems theory and systems thinking require consideration of all the system's features when making organizational changes (Quisenberry, 2018; Shufutinsky, 2019).

Thus, any significant change should consider a whole-system assessment, necessitating a holistic approach to organizational evaluation when contemplating shifts in processes, structures, and strategy (Quisenberry, 2018; Shufutinsky, 2019), including a severe look at organizational leadership and management. This can be especially important when there is a drastic, dramatic, or unexpected shift, including shifting into virtual work environments (Burrell, 2020). Such changes may also require a considerable emphasis on using an advanced adaptive leadership style, such as Shock Leadership, that employs multiple leadership styles and a diversity of leadership attributes simultaneously, as necessary when the change is in response to an event that shocks or jolts the entire system, such as COVID-19 (Shufutinsky et al., 2020a). Through an advanced leadership approach such as this one, managers can be prepared to effectively respond to systemic organizational changes and address challenges such as transitions to telework and virtual team-building (Burrell, 2020).

Additionally, as organizational leaders and managers consider the challenges that may arise with telework programs, including the development of effective virtual teams, team-building can be critical to creating functional virtual groups and team processes (Burrell, 2020). 


\subsection{Team Building}

Team building is vital to ensuring that team members can work effectively and engage the group dynamics to address and manage potential conflicts (Quisenberry, 2018). Team building activities can be and are usually achieved through a diversity of processes, and it can be argued that no two teams require the same team-building techniques (Quisenberry, 2018). Team building activities generally range in methods and approaches. They are implemented to help groups improve how they accomplish tasks, make decisions together, and affect sense-making, communication, decision-making, problemsolving, and resource maximization for organizational performance (Cummings \& Worley, 2001). These exercises can range in focus, concentrating on elements such as task accomplishment, role analysis, role negotiation, and relationship building (French \& Bell, 1999).

\section{Methodology}

To develop a framework for understanding the appreciative qualities and useable telework applications at XRO, a real estate title company. The name XRO is used for this study to protect the actual firm's privacy and intellectual property that produced this data. Focus groups were conducted related to telework. A core principle of action and applied research includes the organization participants who have historical knowledge and implement the recommendations and benefit from the solutions. The applied qualitative research focus group consisted of 20 participants divided into five small discussion groups of 4 individuals developed by opportunistic sampling from organizational employees. Focus group participants included participants (Ten managers and ten employees) that had never previously engaged in telework before COVID-19. The group was mixed with an equal number of managers and an equal number of employees.
Qualitative focus group research provides a unique and essential way to capture the unique knowledge and perspective of observers and subject matter experts on a particular phenomenon (Barbour \& Kitzinger, 1999). Data collected from focus groups can disentangle links and distinctions of exactly how events, experiences, and interactions manifest within a specialized organizational environment Barbour \& Kitzinger, 1999).

The focus group sittings included three doctoral trained professionals. One led the discussions, while the other two functioned as observers and peer reviewers as a validity measure. The process had group brainstorming sessions with responses captured on flip charts. Each group engaged in a report out process where answers were categorized to create a master list of themes, reactions, and concepts with no duplicates.

\section{Results}

The questions and decisive responses were the results of participant selections of the most critical and vital perspectives. The results were as follows:

1. What do you see as reasons for the difficulty in making telework work beyond COVID-19 in your workplace?

- A rigid organizational culture.

-A shortage of financial resources.

-A need for proper managerial support.

- An absence of suitable technology and software tools.

- The existence of burdensome paperbased practices.

- The presence of data and cybersecurity threats.

- A shortage of a fully developed and vetted strategy to support teams switching to teleworking.

2. What are the most positive benefits and attributes of having an effective telework program at XRO? 
- Teleworking offers flexibility and autonomy in a way that empowers employees to work independently.

- Virtual work lowers impending energy costs and expenditures because of fewer workers in an office that must be lit, cooled, or heated.

- Fewer personnel in cars commuting to work reduces car generated carbon emissions.

-Working from home permits employees to be more focused and productive for employees that can effectively leverage technology and a flexible schedule. Deadlines permitting, workers can work early in the day or late at night without the office's distractions.

- Work from home eliminates the delays and pitfalls of bad weather and traffic; employees can focus immediately on looming work projects.

- Virtual working options shrink rental and real estate costs. Less desk or office space is needed because fewer employees are in the office, which reduces sharing and storage options.

- Telework allows employers to reduce parking expenses, which lowers company overhead.

- Telework allows employees to eliminate commuting costs for gas or public transportation.

- Telework allows employees to reduce wear, tear, and maintenance costs on their automobiles because they do not drive to work every day.

- Telework supports an organization's business continuity strategy by putting processes in place to continue business operations without needing all employees in one office location.

- Work from home expands a company's ability to recruit employee talent and expertise outside of the local geographical area.

3. What do you see as the disadvantages of telework?

- Communication can be more difficult when you cannot always talk to others face to face.
- There can be feelings of isolation when working from home instead of being in the office every day.

- Telework can lead to challenges to maintaining a healthy work and personal life balance.

- Workers can increase household expenses for things like Internet service, telephone service, electricity, and utilities.

4. What can employees do to create work-life balance when teleworking?

- Workers need to set clear-cut limits around work start and stop times every day.

- Workers need to have a clear understanding of their expectations, work priorities, communication standards from their boss.

- Workers might need to establish boundaries with the family concerning interruptions during work hours at home.

5. What are the positive keys to having a successful telework program?

- The organization must educate managers and all employees on the benefits and value of telework to ensure widespread buy-in.

- The organization needs to have clear rules, policies, and telework procedures.

- Workers need access to appropriate technology, equipment, and software tools required to work effectively from home. Employees must also be trained on how to use the technology, software, and equipment. This includes creating avenues for employees to get technical support when they are having operational challenges.

- Create work agreements on work hours and work availability for all employees.

- Offer employees mental health support for issues like burnout, stress, and feelings of isolation.

- Create a process to reimburse or fund workers who might encounter faster Internet service or other work related expenses. 
- Establish communication norms: Remote teams need to create new standards that establish clarity in communications that bring predictability and certainty to virtual conversations.

- Ensure that workers know when and how they can reach their direct supervisors.

- Clarify the rights and responsibilities of teleworkers regarding their health and safety while working from home.

- Train managers and teleworkers on the importance of taking sufficient rest breaks during the workday and clarifying that such breaks will not have negative career consequences.

- Provide training and guidelines concerning cybersecurity issues and threats for remote workers.

\section{Conclusions}

As the world adapts to the global pandemic, telework has become necessary to continue operational plans in times of crisis. Following the $9 / 11$ attack in the United States, organizations shifted to teleworking, which progressed into a method of disaster preparedness (Guyot \& Sawhill, 2020). During the COVID-19 pandemic, we have seen a global growth in telework at unprecedented levels as workers placed a high value on health and safety.

The development of effective virtual teams is paramount to organizational success in a COVID-19 world. Management must address the challenges of communication, isolation, and health, and teleworkers should be given clear instructions, training, technical support, technological access, health security, and data and identity protection.

This research points to enhancements in several core areas that can determine a bright future for telework. The potential of telework must account for the impact of drastic organizational change due to the introduction of the virtual workspace, precisely its effect on teams, units, and system components. Telework is dependent on technology, a complex and dynamic application, and therefore, leaders must adapt to multiple leadership styles to ensure flexibility in addressing shocks like the COVID-19 pandemic.

\section{Appendix}

Darrell Burrell Self Reflection Leadership Unplanned Circumstances Adaptability Assessment can be used for managers preparing to implement workplace changes like telework.

Below is a self-assessment tool developed for managers forced to manage remote teams because of COVID 19. This tool aims to help managers identify their strengths and find managers that need additional developmental, organizational support.

Darrell Burrell Self Reflection Leadership Unplanned Circumstances Adaptability Assessment (2020).

$5=$ Always $\quad 4=$ Very often

$3=$ Sometimes $2=$ Not very often $1=$ Rarely, if ever. WITH 5 BEING VERY HIGH AND 1 BEING VERY LOW, CIRCLE THE NUMBER THAT BEST MATCHES YOUR TRUE SELF ASSESSMENT OF YOUR LEADERSHIP ADAPTABILITY SKILLS DURING AN UNEXPECTED AND URGENT SITUATION REQUIRING YOU TO LEAD CHANGE: 5=Always $4=$ Very often $3=$ Sometimes $2=$ Not very often $1=$ Rarely, if ever

The questions should be answered in the context of unexpected and urgent circumstances in need of attention.

1. I insistently pursue crucial data, evidence, and knowledge. 54321

2. I use a variety of approaches to consistently and frequently communicate information, activities, and results to stakeholders on a variety of levels. 54321

3. I am proactive and not reactive in ways that necessitate initiative during unexpected and urgent conditions. 54321 
4. I am a critical, strategic, and clear thinker in stressful conditions. 54321

5. I display emotional intelligence, emotional self-regulation, and calm during unexpected and urgent situations. 54321

6. When change is needed, I embrace it quickly and focus on creating paths that help others see how the necessary transition can occur. 54321

7. I am encouraging, optimistic, and in ways that attempt to find possibilities from solving problems. 54321

8. I am resourceful, innovative, and creative when it comes to problem-solving. 54321

9. I am mentally strong and recover quickly from setbacks. 54321

10. I behave fearlessly and take calculated risks. 54321

11. I make decisions and come to conclusions in a timely and decisive fashion. 54321

12. I create a clear path and vision concerning problems and solutions. 54321

13. I value expertise and knowledge and am committed to continuous learning and development. 54321

14. I think it is imperative to display respect, authentic concern, and empathy when working with others on complex problems. 54321

15. I attempt to identify each employee's strengths and try to find projects and opportunities for them to leverage and develop and display those strengths, competencies, and abilities. 54321

\section{ADD UP YOUR RESPONSES FROM EACH OF THE QUESTIONS AND CALCULATE YOUR SCORES: 65-75: Highly competent Adapter -} You have the qualities necessary to lead change and respond appropriately to unexpected problems, crises, urgent circumstances. You have the skills and abilities that could allow you to assist those less skilled through mentoring and collaboration.

64-51: Serviceable Adapter - You have the qualities necessary to lead change and respond appropriately to unexpected problems, crises, urgent circumstances, but you could strengthen some areas to be more productive. Note the areas where you scored less than a five and focus your attention on improving them.

51-38: Slight Adapter - While you have some strong leadership qualities, you still have plenty of room for improvement to lead change successfully and respond appropriately to unexpected problems, crises, urgent circumstances by focusing on any areas where you did not score a 5 . You could probably benefit from having a highly competent adapter as a mentor.

37 or less: Apprentice Adapter You need to focus your professional development activities on enhancing the skills and abilities to lead change and respond appropriately to unexpected problems, crises, urgent circumstances through a focus on any areas where you did not score a 5. You could probably benefit from having a highly competent adapter as a mentor.

Darrell Burrell Self Reflection Leadership Unplanned Circumstances Adaptability Assessment (Darrell Burrell, 2020) 


\section{REFERENCES}

Alvesson, M. (2004). Knowledge Work and Knowledge-Intensive Firms. Oxford: Oxford University Press.

Barbour, R., \& Kitzinger, J. (1999). Developing focus group research: politics, theory, and practice. Los Angeles: Sage Publications.

Bartunek, J.M., \& Woodman, R.W. (2015). Beyond Lewin: Toward a temporal approximation of organization development and change. Annual Review of Organizational Psychology and Organizational Behavior, Vol. 2, 157-182.

Baruch, Y., \& Nicholson, N. (1997). Home, Sweet Work: Requirements for Effective Home Working. Journal of General Management, Vol. 23, 15-30.

Belzunegui-Eraso, A., \& Erro-Garces, A. (2020). Teleworking in the context of the COVID-19 crisis. Sustainability, J58; J81; F6.

Boje, D.M. (2019). Organizational research: Storytelling in action. New York, NY: Routledge.

Boje, D.M., Oswick, C., \& Ford, J.D. (2004). Language and organization: The doing of discourse. Academy of Management Review, Vol. 29, Issue 4, 571-577.

Bridges, W. (1991). Making the most of change. Managing Transitions. Reading, MA: Addison-Wesley.

Bridges, W. (2004). Transitions: Making sense of life's changes. Lebanon, IN: Da Capo Lifelong Books.

Bridges, W. (2009). Managing transitions: Making the most of change. Lebanon, IN: Da Capo Press.

Bridges, W., \& Mitchell, S. (2000). Leading transition: A new model for change. Leader to Leader, Vol. 16, Issue 3, 30-36.

Brisson-Banks, C.V. (2010). Managing change and transitions: A comparison of different models and their commonalities. Library Management, Vol. 31, Issue 4/5, 241-252.

Burrell, D., Barnard-Zaffino, M., \& Ulomi, S. (2014). An applied research analysis of telework programmes as an environmentally-friendly policy and a viable sustainability development leadership practice. International Journal of Environmental Policy and Decision Making (IJEPDM), Vol. 1, No. 2.

Burrell, D.N. (2019). A Contextual Exploration of the Emergence of Technical Sociology in the Realm of Organizational Technology Management and Cybersecurity Management. International Journal of Engineering Sciences \& Research Technology. Vol. 8, Issue 3. DOI: 10.5281 /zenodo. 2607817

Burrell, D.N. (2020). Understanding the talent management intricacies of remote cybersecurity teams in covid-19 induced telework organizational ecosystems. Land Forces Academy Review, Vol. 25, Issue 3, 232-244.

Bushe, G., \& Marshak, R. (2009). Revisioning Organizational Development: Diagnostic and Dialogic Premises and Patterns of Practice. Journal of Applied Behavioral Sciences, Vol. 45, 348-368.

Buttazzoni, M. (2009). From workplace to anyplace, assessing the opportunities to reduce greenhouse gas emissions with virtual meetings and telecommuting. World Wildlife Fund.

Chan, J.K., Beckman, S.L., \& Lawrence, P.G. (2007). Workplace design. A new managerial imperative. California Management Review, Vol. 49, Issue 2, 6-22.

Chung, H., (2018). Future of Work and Flexible Working in Estonia: The case of employee-friendly flexibility. Available at: http://www.wafproject.org 
Ciulli, F., \& Kolk, A. (2019). Incumbents and business model innovation for the sharing economy: Implications for sustainability. Journal of cleaner production, 214, 995-1010.

Clements-Croome, D.J., \& Kaluarachchi, Y. (2000). Assessment and measurement of productivity. Creating the Productivity Workplace: 129-166. Spon: Routledge.

Connelly, F.M., \& Clandinin, D.J. (2006). Narrative inquiry. In J. L. Green, G. Camilli, \& P. B. Elmore (Eds.), Handbook of complementary methods in education research. ( $3^{\text {rd }}$ Edition, pp. 477-487). Mahwah, NJ: Erlbaum.

Cooperrider, D. (1986). Appreciative inquiry: Toward a methodology for understanding and enhancing organizational innovation. (Doctoral dissertation). Available on: ProQuest Digital Dissertations. (AAT 8611485)

Cooperrider, D., \& Srivasta, S. (1987). Appreciative inquiry in organizational life. In R.W. Woodman \& W.A. Pasmore (Eds.). Research in organizational change and development (Vol. 1, pp. 129-169). Stamford, CT: JAI Press.

Cooperrider, D., \& Whitney, D. (1999). A positive revolution in change: Appreciative inquiry. Taos, NM: Corporation for Positive Change.

Cooperrider, D., \& Whitney, D. (2005). Appreciative inquiry: A positive revolution in change. Chicago: Berrett-Koehler Publishers.

Cummings, T., \& Worley, C. (2001). Organization development and change. $7^{\text {th }}$ Edition, Cincinnati, OH: Southwestern College.

Cummings, T., \& Worley, C. (2008). Organization development and change. Mason, $\mathrm{OH}$. South Western.

Deshpande, A., Sharp, H., Barroca, L., \& Gregory, P. (2016). Remote working and collaboration in agile teams. ICIS Conference on Managing is Projects and is Development.

Evangelakos, G. (2020). Keeping critical assets safe when teleworking is the new norm. Network Security, Vol. 6, 11-14.

Gelston, G.M., Wells, C., \& Dalton, A. (2018, June). Virtual leadership in complex multiorganizational research and development programs. IEEE Conference on Cognitive and Computational Aspects of Situation Management (CogSIMA).

Green, D.D. (2018). Fueling the gig economy: a case study evaluation of Upwork.com. Management and Economics Research Journal, Vol. 4, 3399.

Guyot, K., \& Sawhill, I., (2020). Telecommuting will likely continue long after the pandemic. The Brookings Institution, available at: https://www.brookings.edu/blog/upfront/2020/04/06/telecommuting-will-likely-continue-long-after-the-pandemic/

Hagy, M.R. (2018). Trust at no sight: Establishing trust in the process rather than in the individual members of a global virtual team. Temple University.

Ilie, M., Ilie, C., \& Marin, R. (2020). Human Resources and Communication Management after Changes Due to COVID 19 pandemic. Ovidius University Annals, Series Economic Sciences, Vol. 20, Issue 1.

Katsabian, T. (2020). The telework virus: How the covid-19 pandemic has affected telework and exposed its implications for privacy and equality. Available at: http://dx.doi.org/ 10.2139/ssrn.3684702

Kim, V., \& Coghlan, A. (2020). Measuring the Factors of Teleworking Productivity and Engagement in a New Reality of COVID-19: The Case of Austria, Germany, and Russia. Doctoral dissertation, Wien.

Leung, L. (2004). Societal, organizational, and individual factors in the adoption of telework. Impact and issues in news media: Toward intelligent societies, 149-171.

Marshak, R.J. (1993). Lewin meets Confucius: a review of the O.D. model of change. Journal of Applied Behavioral Sciences, Vol. 29, 393-415. 
Martin, K.A. (2018). Study of productivity rates for geographically distributed agile teams. Doctoral dissertation, Northcentral University.

Merriam, S. (1998). Qualitative research and case study applications in education. San Francisco, CA: Jossey Bass.

Niles, J. (1999). Integrating telework, flextime, and officing for workforce 2020. Hudson Institute Center for Workforce Development.

O’Keefe, S. (2008). Shifting Federal Telework into Drive. Public Manager. Vol. 37, Issue 1, 47-49.

Papmehl, A. (2001). Remote Access. CMA Management, Vol. 75, Issue 3, 11.

Quisenberry, W.L. (2018). Exploring how emotional intelligence contributes to virtual teams: Interpretive analysis of a phenomenological study. European Scientific Journal, Vol. 14, Issue 5, 19-36.

Rosengren, C., Ottosson, M., Daniels, J., Gregory, K., \& Cottom, T.M. (2017). Employee monitoring in a digital context. Digital sociologies, 181-194.

Rousseau, D.M. (1977). Technological differences in job characteristics, employee satisfaction, and motivation: A synthesis of job design research and socio-technical systems theory. Organizational Behavior and Human Performance, Vol. 19, Issue 1, 18-42.

Schein, E.G. (1999). Process Consultation Revisited: Building the Helping Relationship. Reading, MA. Addison-Wesley.

Schlossberg, N.K. (1981). A model for analyzing human adaptation to transition. The Counseling Psychologist, Vol. 9, Issue 2, 2-18.

Schlossberg, N.K. (2011). The challenge of change: The transition model and its applications. Journal of Employment Counseling, Vol. 48, Issue 4, 159-163.

Shaver, K. (2003). Steering Employers Toward Telework. The Washington Post. pg. B.01.

Shin, B., El Sawy, O.A., Sheng, O.R.L., \& Higa, K. (2000). Telework: Existing research and future directions. Journal of Organizational Computing and Electronic Commerce, Vol 10, Issue 2, 85-101.

Shufutinsky, A. (2019a). From Salutes to Staff Meetings: A Triangulated Qualitative Inquiry Study of the Experiences of Wounded Warriors in Post-Military Corporate Positions. ProQuest Dissertations.

Shufutinsky, A. (2019b). Holoportation: An Innovation That Will Disrupt and Transform Organization Development and Management Consulting. Journal of Leadership and Innovation Management, Vol. 5, Issue 1, 1-34.

Shufutinsky, A. (2020). Employing Use of Self for Transparency, Rigor, Trustworthiness, and Credibility in Qualitative Organizational Research Methods. Organization Development Review, Vol. 52, Issue 1, 50-58.

Shufutinsky, A., DePorres, D., Long, B., \& Sibel, J. (2020). Shock Leadership Development for the Modern Era of Pandemic Management and Preparedness. International Journal of Organizational Innovation, Vol. 13, Issue 1, 1-23.

Shufutinsky, A., Sibel, J., Murray Hayden, P., Shufutinsky, D., \& Cox, R. (2018). Holoportation: The Disruptive Technology that Will Change the Practice of Conflict Analysis and Resolution. O.D. Practitioner, Vol. 50, Issue 3.

Shufutinsky, A., Sibel, J.R., Beach, A.A., \& Saraceno, A.J. (2020). O.D. for Robots? Industry 4.0, Emerging Technologies and the Implications on Organizational Talent Acquisition and Development Practices. Organization Development Journal, Vol. 38, Issue 3.

Silva, A.L., \& Merino, G.S.A. (2017). Potentialities of remote teams in the innovation process in an organization through the design management. Strategic Design Research Journal, Vol. 10, Issue 3, 204-214. 
Tan-Solano, M., \& Kleiner, B. (2001). Effects of telecommuting on organizational behavior. Management Research, Vol. 24, Issue 3/4.

Taskin, L., \& Bridoux, F., (2010). Telework: A challenge to knowledge transfer in organizations. International Journal of Human Resource Management, Vol. 21, Issue 13, 2503-2520.

Thatchenkery, T., \& Metzker, C. (2006). Appreciative Intelligence: Seeing the mighty oak in the acorn. San Francisco, CA. Berrett-Koehler.

The Climate Group. (2008). SMART 2020: Enabling the low carbon economy in the information age.

United States Bureau of Transportation Services. (2006). Transportation Implications of Telecommuting. National Transportation Library a Program of the Bureau of Transportation Services.

Vaughn, S., Schumm, J.S., \& Sinagub, J. (1996). Focus Group Interviews on Education and Psychology. Thousand Oaks, CA: Sage.

Verive, J., \& DeLay, N. (2006). Measuring telework ROI: Metrics based on the employee life cycle. World at Work Journal, Vol. 15, Issue 2.

Walker, G.H., Stanton, N.A., Salmon, P.M., \& Jenkins, D.P. (2008). A review of sociotechnical systems theory: a classic concept for new command and control paradigms. Theoretical Issues in Ergonomics Science, Vol. 9, Issue 6, 479-499.

Watson Wyatt Worldwide. (2000). Human Capital Index Report. Washington, DC: Watson Wyatt Publishing.

Wendell, L.F., \& Cecil, B. (1999). Organization development: Behavioral science interventions for organization improvement. Pearson College Division.

Wojcak, E., Bajzikova, L., Sajgalikova, H., \& Polakova, M. (2016). How to achieve sustainable efficiency with teleworkers: Leadership model in telework. Procedia-Social and Behavioral Sciences, Vol. 229, 33-41. 